\title{
A EDUCAÇÃO PROFISSIONAL DE NÍVEL TÉCNICO E A ESTRATÉGIA SAÚDE DA FAMÍLIA : RENOVA-SE O DESAFIO
}

\author{
Milta Neide F.B. Torrez ${ }^{1}$ \\ Lília Romero de Barros ${ }^{2}$ \\ Valéria Morgana Penzin Goulart ${ }^{3}$
}

\section{INTRODUÇÃO}

Este tema diz respeito a relação entre os processos de profissionalização dos trabalhadores de "nível médio" 4 e as políticas de educação e saúde, uma das questões mais instigadoras no campo da educação profissional e que tem a capacidade de mobilizar tanto as pessoas quanto as instituições.

Sua complexidade reside no fato de abordar questões de natureza político-social que envolvem uma ampla rede de atores, contextos e interesses extremamente diversos (e polêmicos) nas visões e razões que os subsidia.

Como é preciso contextualiza-la na estratégia Saúde da Família, que articulou os Programas Saúde da Família e Agentes Comunitários de Saúde -PSF/PACS, seria

Por estas razões, um dos aspectos mais criticáveis, presente de forma acentuada na Reforma da Educação Profissional, é justamente a aceitação e justificação destes conflitos como se fossem desafios "naturais" do mundo contemporâneo, o que inclui o desemprego, a competitividade desenfreada, a economização e monetarização da vida social e pessoal, a ênfase na competência profissional como mercadoria.

impossível montar este "quebra-cabeças" apenas nos limites específicos deste texto, ficando a compreensão mais completa desta questão a cargo do conjunto desta edição especial.

Serão tratados aqui alguns aspectos da Educação Profissional de Nível Técnico dirigida aos trabalhadores de "nível médio", o que inclui os que atuam na Saúde da Família, buscando relações ${ }^{5}$ entre os objetivos político-assistenciais preconizados e os objetivos pedagógicos, que devem ser coerentes com aqueles, em termos dos princípios e práticas.

Partirá do pressuposto que depende do estabelecimento dessas relações político-pedagógicas a capacidade do setor saúde ordenar a profissionalização de modo compatível com a "trabalhabilidade"6 contemporânea, sem perder de vista o objetivo de promover a prestação de cuidados contextualizada", baseada no Paradigma da Vigilância/Promoção da Saúde e nos princípios do Sistema Único de Saúde - SUS. Os aspectos a serem bordados são:

De que educação profissional estamos falando hoje? A Estratégia Saúde da Família e a Educação Profissional: novas relações político-pedagógicas; Itinerários educativos: o que é isto ?

\section{DE QUE EDUCAÇÃO PROFISSIONAL ESTAMOS FALANDO HOJE?}

Do ponto de vista dos órgão governamentais e das políticas públicas de educação e trabalho,

${ }^{1}$ Enfermeira, Mestre em Educação, ex diretora geral da Escola de Form. Técnica em Saúde Enfa. Izabel dos Santos SES/RJ.

${ }^{2}$ Enfermeira , Especialista em Enfermagem na Saúde da Família e da Comunidade pela Univ. do Estado do Rio de Janeiro -UERJ SES-RJ

${ }^{3}$ Enfermeira , Instrutora do Polo de Capacitação de Pessoal para a Saúde da Família/ Núcleo UERJ/ 
está em curso a emergência de um novo modelo que altera radicalmente o panorama da Educação Profissional - EP. Está em construção uma "nova institucionalidade ${ }^{8}$, completamente diferente daquela que vem desde os anos 40 e que foi até recentemente amparada pela Lei 5692/71 e Parecer 45/72, já revogados pela Lei de Diretrizes e Bases da Educação Nacional -LDB n ${ }^{\circ}$ 9394/96 e demais regulações específicas para este campo de ação .

Para se falar em Educação Profissional hoje é preciso considerar, mesmo que sinteticamente, que as Reformas Educacionais estão em curso em todos os continentes, cuja tônica é essencialmente a mesma - gerar competências básicas e específicas de interesse do mercado - devido às ações determinadas pelo movimento político-econômico de proteção dos interesses do capital, que assume uma forma globalizada e homogeneizadora, mas não integradora ou inclusiva .

Esta forma de globalização ${ }^{9}$ se desenvolve numa “ (...) velocidade sem precedentes, viabilizada por novas tecnologia microeletrônicas, informacionais e energéticas" 10 e "para entendê-la, como, de resto, a qualquer fase da história, há dois elementos fundamentais a levar em conta: o estado das técnicas e o estado da política" 11.

Na verdade "(...) nunca houve na história humana separação entre as duas coisas. As técnicas ${ }^{12}$ são oferecidas como um sistema e realizadas combinadamente através do trabalho e das formas de escolha dos momentos e dos lugares de seu uso. É isso que fez [e faz a história." Santos acredita que, o que chama de globalização perversa “(...) poderia ser diferente se o uso político fosse outro". ${ }^{13}($ idem, ibidem).

Nesse contexto de aceleração do "mercado global", a relação trabalho - educação também assume uma complexidade sem precedentes, devido, também, aos impactos da evolução tecnológica contemporânea em todos os campos de ação, levando ao uso intensivo de tecnologias informacionais nos mais elementares procedimentos da vida cotidiana e as novas formas de gestão do trabalho que possibilitam o aparecimento e desaparecimento de papéis e práticas profissionais, dentre outros grandes desafios para os chamados países periféricos.

Esses países, devido à forte concentração de renda e seus efeitos - exclusão social, baixas taxas de escolaridade, desqualificação profissional, etc, já teriam que construir alternativas de adequação a este novo contexto mesmo que estivesse em curso uma outra globalização.

Por estas razões, um dos aspectos mais criticáveis, presente de forma acentuada na Reforma da Educação Profissional, é justamente a aceitação e justificação destes conflitos como se fossem desafios "naturais" do mundo contemporâneo, o que inclui o desemprego, a competitividade desenfreada, a economização e monetarização da vida social e pessoal, a ênfase na competência profissional como mercadoria.

Estes fenômenos são apresentados como algo inexorável, enfrentado pela aquisição e busca contínua de condições de empregabilidade que deve estar preparado para as mudanças velozes dos processos produtivos, consolidando assim o discurso único, homogeneizador, tecnicamente avançado mas politicamente conservador para as sociedades marginais ao processo de reconcentração da riqueza, do conhecimento e do poder.

Para alcançar o objetivo de influir convincentemente no imaginário social, esta forma de globalização utiliza-se principalmente das tecnologias de comunicação e informação, cujo nível de desenvolvimento atual faz crer que longe é um lugar que nunca existiu mesmo; que todos se tornaram "globais mesmo sem o devido acesso aos benefícios trazidos por tal estágio de desenvolvimento das técnicas.

Fica evidente que apesar dos princípios enunciados nos textos oficiais, a (r)evolução tecnológica não teve o seu correspondente na política, já que esta, não está mudando de fato as velhas formas das relações sociais.

Outro aspecto lamentável é o conhecimento para o trabalho, um histórico e fundamental componente da formação humana, ser dirigido exclusivamente à produção de laboralidade, ao desenvolvimento de determinadas aptidões para a vida produtiva referenciada focalmente no mercado e suas demandas, sendo regulamentado sob a forma de educação profissional de modo a preservar o controle e o "ajuste do foco" ${ }^{14}$ aos fins político-econômicos definidos prioritariamente pelo contexto internacional. 
Frente ao que consta nos textos oficiais e legais, esta nova visão da Educação Profissional crê que o mercado pode assumir outros interesses que não os condizentes com a sua natureza lucrativa e acumulativa ou, que suas demandas possam ser naturalmente de interesse social, geradoras de equidade, como cabe, necessariamente, às políticas sociais.

Diante do que foi dito entende-se que essas políticas, concebidas e implementadas pela articulação entre o Ministério do Trabalho e Emprego e o Ministério da Educação, estão integrando o conjunto de estratégias para a consolidação do modo capitalista de produção no Brasil, o que implica em dar à educação profissional a função de fator de desenvolvimento econômico, que, nele, sempre marcou a sua história, demonstrando que nesse caso não está fazendo algo realmente novo.

Assim como, é possível identificar criticamente a "velha" matriz da nova educação profissional, também é possível perceber a contradição estabelecida entre a intencionalidade de libertar "a criatividade, a utopia, a ousadia, a autonomia escolar"15, e a implantação de típicos mecanismos de controle representados pelas Diretrizes Curriculares - definidas com força de lei; os Referenciais Curriculares por área de produção que pretendem subsidiar a elaboração dos perfis profissionais e a reconceitualização e estruturação dos currículos; a "checagem" dos resultados mediante a avaliação e certificação baseadas em competências e a criação do Sistema Nacional de Certificação de Competências.

É identificável ainda que os textos da Reforma "acenam com acertos conceituais aceitáveis"16 quando incorporam alguns princípios já reconhecidos como norteadores de uma educação competente e emancipadora, tais como: flexibilidade, contextualização, interdisciplinaridade, significação, ética, dentre outros.

Uma diferença básica entre ela e outras visões político-pedagógicas, é que estes princípios embasam a educação para o trabalho indissociável do processo de formação humana para a cidadania, para ser alcançada pelos brasileiros e não só por aqueles que estão, conjunturalmente, na força de trabalho.

Cidadania na qual, saúde e educação - apresentando-se sob a forma de trabalho profissional ou bem de consumo - sejam direitos de todos. Na Reforma, ela dever ser primordial e objetivamente orientada para a “(...) trabalhabilidade, [entendida como] componente da dimensão produtiva da vida social e portanto da cidadania"17, porém, acaba sendo orientada pelo mercado e efetivamente circunscrita ao contexto profissional.

Entende-se portanto, que reside na capacidade crítica de interpretar e recontextualizar ${ }^{18}$ os princípios e estratégias contidos na Reforma, a possibilidade das instituições educacionais identificarem e construírem estratégias profissionalizadoras condizentes com as necessidades sociais e técnicoprofissionais dos trabalhadores de nível médio atuantes na Saúde da Família, aperfeiçoando a coerência entre discurso e prática.

Uma vez que profissionalizar ${ }^{19}$ os recursos humanos para essa Estratégia, de forma coerente e competente também não é uma questão nova, renova-se o desafio, acrescido das implicações de evitar que leituras lineares ou corporativas que ignorem essa nova institucionalidade, possam gerar perdas para a "laboralidade" dos trabalhadores de nível médio no mercado de trabalho em saúde, e complexificado pela própria reorientação do modelo assistencial que pretende extrapolar o nível da atenção básica, voltando-se para a totalidade da população brasileira e envolvendo todos os trabalhadores do Sistema. ${ }^{20}$

É preciso evitar também que ocorram desvios dos seus propósitos político-programáticos específicos, dependendo da relação estabelecida com a "lógica do mercado" ou que, ignorando o paradigma em implantação na Educação Profissional, sejam deixados à margem daquilo que pode ser construtivo para a sua cidadania. Por isso é necessário avançar nessa reflexão.

\section{A ESTRATÉGIA SAÚdE DA FAMÍLIA E A EDUCAÇÃO PROFISSIONAL : NOVAS RELAÇÕES POLÍTICO-PEDAGÓGICAS}

Para o desenvolvimento deste tópico, é importante considerar que não faz parte do objetivo deste artigo a discussão sobre os aspectos conceituais e programáticos da estratégia Saúde da Família. Partirá do fato que os programas Agentes Comunitários de Saúde-PACS e Saúde da Família- 
PSF estão articulados e apontados como a estratégia política para o setor saúde que deve reordenar a atenção básica e catalisar a reorientação do modelo assistencial.

Conforme declaram os textos oficiais que norteiam as experiências locais, tal reorientação está baseada no Paradigma da Vigilância em Saúde e nos princípios do SUS ${ }^{21}$.

Diante de um papel dessa envergadura na política pública setorial, essa estratégia precisa ser seriamente considerada na definição de novas relações político-pedagógicas com a educação profissional, visando os trabalhadores de nível médio que nela atuam, assim como ,os demais que atuam no SUS e estarão inseridos no modelo assistencial reorientado.

Ao seu modo, estará exemplificando a determinação social da educação já discutida no tópico anterior, na qual a estrutura social traduz os seus objetivos políticos em objetivos pedagógicos, de forma socialmente construtiva.

Por isso é importante ressaltar, que apesar de muitas vezes a relação sociedade - educação ser estabelecida de forma insatisfatória, não pode ser negada, pois, do encontro do projeto societário com a expressão da educação que lhe seja mais coerente surgem importantes condições para a sua construção.

Daí a relevância das relações político-pedagógicas em qualquer tipo de sociedade, principalmente para os projetos estruturantes, como é considerada a estratégia Saúde da Família no campo dos serviços de saúde ${ }^{22}$.

Para o estabelecimento dessas relações, no contexto do "novo" paradigma da Educação Profissional, uma articulação que está colocada como obrigatória é aquela entre os princípios gerais e específicos da EP, o perfil do trabalhador de nível médio contemporâneo e suas competências gerais e específicas, uma vez que subsidiarão os projetos pedagógicos das Instituições e Cursos e as certificações. Vejamos como a legislação educacional os apresenta.

Este trabalhador necessita da escolaridade básica que "constitui condição indispensável para o êxito num mundo pautado pela competição, inovação tecnológica e crescentes exigências de qualidade, produtividade e conhecimento"23;"precisa ter competências para transitar com maior desenvoltura e atender as várias demandas de uma área profissional, não se restringindo a uma habilitação vinculada especificamente a um posto de trabalho(.. . $)^{24}$, o que justifica que as diretrizes curriculares nacionais estejam centradas no conceito de competências por área.

Deste modo, "do técnico será exigido tanto uma escolaridade básica sólida, quanto uma educação profissional mais ampla e polivalente", pois deverá atender à exigência, " em doses crescentes, [de] maior capacidade de raciocínio, autonomia intelectual, pensamento crítico, iniciativa própria e espírito empreendedor, bem como capacidade de visualização e resolução de problemas". idem)

O entendimento sobre competência presente no Parecer CNE/CEB n' 16/99 e na Resolução CNE/CEB n ${ }^{\circ}$ 04/99 ${ }^{25}$, a conceitua como "a capacidade de mobilizar, articular e colocar em ação valores, conhecimentos e habilidades necessários para o desempenho eficiente e eficaz de atividades requeridas pela natureza do trabalho", deixando clara a necessidade da aquisição de competências básicas construídas ao longo de um processo de escolarização, onde os esquemas mentais tiveram tempo e condições para serem estruturados.

Esse modo, as s competências requeridas pela educação profissional são: I - competências básicas, constituídas no ensino fundamental e médio, II -competências gerais, comuns aos técnicos da área profissional e III - competências específicas de cada habilitação. .

Os princípios incluem o da articulação com o ensino médio, os comuns com a educação básica - que são os referentes aos valores estéticos, políticos e éticos e aqueles que definem sua identidade e especificidade ou seja, que se referem ao desenvolvimento de competências para a laboralidade, tais como: a flexibilidade, a interdisciplinaridade , a contextualização na organização curricular, a identidade dos perfis profissionais de conclusão, a atualização permanente dos cursos e seus currículos e a autonomia da escola em seu projeto pedagógico.

Diante desse contexto e frente ao papel estratégico que lhe é atribuído, caberá à Estratégia Saúde da Família estabelecer novas relações político-pedagógicas para a formação profissional dos trabalhadores de nível médio em saúde, inclusive daqueles que nela atuam, subsidiando a construção coletiva dos projetos educacionais a serem promovidos. Exemplificando: 
I - Possibilitar e estimular a conquista da educação básica - nível fundamental e médio como requisito para se ter e promover saúde, uma vez que a educação é um dos fatores determinantes porque também possibilita o acesso ao conhecimento, aos bens materiais e culturais, reconhecidos como estruturantes da qualidade de vida cidadã.

II -Investir na construção e execução de Projetos Pedagógicos que expressem o conceito de competência humana ${ }^{26}$ para o cuidar em saúde, implicando na capacidade política de reconhecer e assumir a responsabilidade do cuidado partindo da concepção de saúde como qualidade de vida, e agir mobilizando conhecimentos, habilidades, atitudes e valores exigidos pelas situações concretas , na promoção/produção do cuidado requerido.

III-Acolher o paradigma político-asssistencial como referência político-pedagógica, cujos princípios reorientarão as propostas educativas e recontextualizarão os princípios da Educação Profissional, o perfil de conclusão do egresso e as competências a serem desenvolvidas.

III - Orientar o perfil de conclusão dos egressos no que tange às competências gerais como resultante da leitura articulada das mesmas, de modo a preservar a perspectiva integralizadora das concepções e práticas e incorporar contribuições sociológicas. antropológicas, culturais e políticas para a contextualização do ato de cuidar, visando a qualidade de vida.

IV -Embasar a definição das competências específicas nos objetivos político-operacionais presentes (e a serem incorporados) nas diretrizes programáticas, composição da equipe, leque de atribuições e outras mediações para a reorganização das práticas assistencias e de trabalho. Consequentemente, estimular habilidades e atitudes que expressem a compreensão da integralidade dos fenômenos observados, o que leva a incorporar os princípios da intersetorialidade, interdisciplinaridade, responsabilização individual e coletiva, mediados pela dimensão ético-política.

$\mathrm{VI}$-Possibilitar a integração teoria-prática pela articulação ensino-serviços-comunidade, mediante o desenvolvimento da formação profissional nos ambientes onde a Saúde da Família se desenvolve, como 'recurso metodológico" fundamental para a aquisição das competências profissionais requeridas pelo cuidar, situado nos mais diferentes espaços e tempos - institucional, domiciliar, comunitário- e com as mais diversificadas clientelas.

VII - Reconhecer como princípio pedagógico, que a competência para o trabalho em saúde é parte da formação humana dos trabalhadores, que "humanizando o conhecimento"27 pode implementar a humanização do cuidado, servindo aos fins éticos.

\section{ITINERÁRIOS EDUCATIVOS : O QUE É ISTO ?}

A regulamentação sobre Educação Profissional contida no Decreto 2.208/97 determina no Artigo $1^{\circ}$ que entre os seus objetivos está:

“(...)proporcionar a formação de profissionais, aptos a exercerem atividades específicas no trabalho, com escolaridade correspondente aos níveis médio, superior e de pós-graduação; especializar, aperfeiçoar e atualizar o trabalhador em seus conhecimentos tecnológicos; qualificar, reprofissionalizar e atualizar jovens e adultos trabalhadores, com qualquer nível de escolaridade, visando a sua inserção e melhor desempenho no exercício do trabalho.

Diante das exigências de transitar e atender as várias demandas de uma área profissional, rever e atualizar permanentemente os seus currículos ${ }^{28}$ além da complexidade específica da atuação na estratégia de Saúde da Família , na qual a "incorporação tecnológica se dá, basicamente, no nível do conhecimento"29 é necessário oferecer este leque de possibilidades e estabelecer um "itinerário educativo" que poderá ser percorrido pelo trabalhador, a depender das necessidades e possibilidades reais de oferta e acesso, tendo como ponto de partida o nível no qual se encontrar.

É importante evidenciar alguns limites para este percurso pois a E.P compreende três níveis estruturais com suas abrangências e requisitos de acesso, necessitando que se faça uma criteriosa análise do que se quer alcançar especificamente, considerando o ponto de partida, perdas e ganhos.

OS NÍVEIS E SUA ABRANGÊNCIA SÃO:

1- Nível básico: destinado à qualificação e reprofissionalização de trabalhadores, independente 
de escolaridade prévia.( art.3\%); é modalidade de educação não formal, (...) não estando sujeita à regulamentação curricular. (art. $4^{\circ}$ ); os concluintes receberão o certificado de qualificação profissional (art.4 .inc.2).

2-Nível Técnico: destinado a proporcionar habilitação profissional a alunos matriculados ou egressos do ensino médio ( art. $3^{\circ}$ ) ; terá organização curricular própria e independente do ensino médio, podendo ser oferecida de forma concomitante ou sequencial a este (.art. $\left.5^{\circ}\right)$. No Parecer CNE/ CEB n` 16/99 -item 7, está garantido que esse nível

(...) contempla a habilitação profissional propriamente dita de técnico de nível médio(...), as qualificações iniciais e intermediárias, e os módulos ou cursos posteriormente desenvolvidos, complementarmente, de especialização, aperfeiçoamento e atualização.

Faz parte das qualificações iniciais a Qualificação Profissional de Nível Técnico (ex. nível auxiliar) que por integrar "itinerário profissional de nível técnico, poderão ser oferecidos a candidatos que tenham condições de matrícula no ensino médio (ou seja, possuam o ex. ${ }^{\circ}$ grau completo).

O Parecer CNE/CEB n 10/2000 orienta os Conselhos Estaduais de Educação sobre procedimentos para implantar a EP de Nível Técnico, com ênfase nas qualificações iniciais, inclusive a do Auxiliar de Enfermagem.

3-Nível tecnológico: correspondente a cursos de nível superior na área tecnológica, destinados a egressos do ensino médio e técnico.(art. $3^{\circ}$ )

Existe portanto a possibilidade de configurar diferentes itinerários e esses podem ser criativos, flexibilizando o processo de profissionalização, atendendo a especificidades e diferentes necessidades, alcançandò níveis sem precedentes em termos do campo da Educação Profissional.

Isso representa um desafio importante para os Pólos de Capacitação em Saúde da Família em sua articulação com instituições formadoras e/ou diferentes ofertas de capacitação dos recursos humanos.

Para atender às finalidades deste texto, destacaremos agora possibilidades e limites que precisarão ser conquistadas e superados de forma diferente pelos trabalhadores de nível médio, originalmente do PSF e do PACS, através de alguns exemplos .

A- Para aqueles que estão autorizados a exercer a atividade de Agentes Comunitários de Saúde pelo Decreto 3.189/99:

- os treinamentos introdutórios e seqüenciais podem ser "classificados" no nível básico e certificados como Qualificação Básica, independente do nível de escolaridade que os trabalhadores possuam;

- se planejado um curso cuja estrutura curricular esteja organizada sob a forma de um conjunto de módulos ou áreas de estudo ( que visem "terminalidades parciais" com base nas diferentes naturezas das ações que desempenham, por exemplo), cujo requisito de escolaridade seja a educação fundamental ( $\operatorname{ex} 1^{\circ}$ grau completo), poderão obter o certificado de Qualificação Profissional de Nível Técnico.

É importante observar que nesse caso, o curso deverá caracterizar-se como parte de um itinerário profissional de nível técnico. Como ainda não existe uma habilitação técnica em Saúde da Família, seria preciso cria-la , já apontando esta Qualificação como o seu nível inicial, analisadas as implicações para a ordenação dos recursos humanos frente à reorientação do modelo assistencial e outras alternativas aplicáveis aos trabalhadores que já possuam o nível técnico.

Como "estratégia de curto prazo", essa qualificação também poderá representar uma das expressões do itinerário técnico na área de Enfermagem (com "perfil da Vigilância em Saúde"), porque este caminho já está dado e vivenciado pela supervisão técnico-educativa dos ACS, realizada por enfermeiros(as), o que já demonstra tal relação.

B- Aqueles que já dispõem da escolaridade básica (ex $2^{\circ} \mathrm{grau}$ ), egressos ou matriculados, sejam Auxiliares de Enfermagem ou ACS, poderão alcançar a habilitação em nível técnico. Os que a concluírem, poderão fazer cursos de aperfeiçoamento e especialização ( pós-médio), na forma modular , por inteiro ou através de aproveitamento de estudos ( por aproveitamento das competências adquiridas nas qualificações básicas, por exemplo), além de legalmente poderem prosseguir para o nível tecnológico, graduação, pós -graduação...

Neste termos, podemos concluir que profissionalizar é preciso, é possível e pode ser 
profundamente construtivo para a estratégia de Saúde da Família, para o SUS, para a cidadania brasileira, se forem criativa e criticamente aproveitadas as possibilidades da Educação Profissional de Nível Técnico. É fundamental recontextualiza-las frente aos objetivos político-assistenciais, recriando as relações político-pedagógicas e aperfeiçoando a coerência entre o desejo e a prática. Para a Estratégia Saúde da Família, como de resto para todos os que desejam a saúde como expressão do cuidado com a Vida, renova-se o grande desafio.

\section{NOTAS}

4 "Nível Médio "- designação genérica dada aos trabalhadores ou funcionários das Instituições de Saúde, públicas e privadas, cuja escolaridade pode ser de nível fundamental (ex $1^{\circ} \mathrm{grau}$, completo ou incompleto) ou de nível médio ( ex $2^{\circ}$ grau). Em ambos os grupos estão presentes os que não possuem formação profissional específica para o trabalho no setor, caracterizando-os como atendentes ou empíricos.

${ }^{5}$ Neste texto entende-se por relação a existência de nexos entre os aspectos abordados, políticos e pedagógicos, possibilitados pela conexão entre princípios, fatos, estratégias, ou seja, concepções e práticas.

6 Trabalhabilidade, empregabilidade, laboralidade - "conjunto de conhecimentos, habilidades, comportamentos e relações que tornam o profissional necessário não apenas para uma, mas para toda e qualquer organização"; " a capacidade de obter e manter -se empregado, " manter-se competitivo em um mercado em mutação”.(Mehedeff, 1996). Nassim Gabriel Mehedff é secretário de formação e desenvolvimento profissional - SEFOR - Ministério do Trabalho e Emprego - MTb

${ }^{7}$ Contextualizar , considerar onde, quando, por quê, por quem , como, são realizadas as ações, explicitando o (s) espaço (s) específicos em que acontecem, deixando claro "o lugar "de onde se fala.

${ }^{8}$ Nova Institucionalidade"- para o Ministério do Trabalho e Emprego, é a expressão das mudanças que "abrangem o conjunto de leis, normas, tradições, organizações, processos, atores e agentes da Educação Profissional, nos diferentes países da América Latina e Caribe (...)”. (Mehedff, 1997)

${ }^{9}$ Globalização " não é um fenômeno novo e, igualmente, não é algo negativo em si mesmo. A positividade ou negatividade dos processos de globalização e de universalização são definidos, inequivocamente , pelas relações sociais" [que promove], pois "romper as barreiras das cavernas, dos guetos e da província tem sido uma busca constante na construção histórica do ser humano" (Frigotto,2000.p 28)

${ }^{10}$ FRIGOTTO, G. 2000 p 28

"SANTOS, M.2000 p 24.

${ }^{12}$ As técnicas, neste texto de Milton Santos, refere-se e designa a ampla base tecnológica e não alguns procedimentos técnicos.

${ }^{13}$ SANTOS, M.2000 p24

${ }^{14}$ Segundo LEITE, Elenice M. no seu texto sobre Educação Profissional no Brasil: construindo uma nova institucionalidade, "a educação profissional é, por sua vez, esfera de interface do MEC e MTb, com vistas ao permanente "ajuste de foco" que esta atividade deve ter ." (1996, p. 6)

${ }^{15}$ BRASIL. MEC, Referenciais Curriculares para a educação profissional de nível técnico. Texto introdutório., Versão preliminar. SEMTEC/CGEP, Brasília, DF: 2000, p. 11 (mímeo)

${ }^{16}$ CEPAL opus cit in DEMO,1997 p8 
${ }_{17}$ BRASIL. MEC. Referenciais Curriculares para a educação profissional de nível técnico. Texto introdutório., Versão preliminar. SEMTEC/CGEP, Brasília, DF: 2000, p. 6 ( mímeo).

${ }^{18}$ Recontextualização: é entendida como um processo de reposicionamento das concepções e práticas, promovendo a releitura das propostas iniciais, que são inseridas em contextos específicos permitindo mudanças, adaptações aos seus significados originais.

19 Profissionalizar significa educar profissionalmente. Hoje é, a rigor, tudo o que ocorre após o ensino médio, incluindo o ensino técnico e tecnológico, os cursos sequenciais por campo de saber e os demais cursos de graduação. Todos são considerados como cursos de educação profissional.

${ }^{20}$ BRASIL, MS, 1999 p 10

${ }^{21}$ BRASIL, MS, 1997 p8 - 18 e BRASIL MS, 1999 p10

${ }^{22}$ Ver MENDES, E.V.1999,p 258-284

${ }^{23}$ A educação básica "tem por finalidades desenvolver o educando, assegurar-Ihe a formação comum indispensável para o desenvolvimento da cidadania e fornecer-lhe meios para progredir no trabalho e em estudos posteriores" - LDB n9.394/96 Capítulo II - Da Educação Básica , Seção I , Das Disposições Gerais, art.22

${ }^{24}$ BRASIL. MEC. Parecer CNE -CEB n 16/99- Diretrizes Curriculares Nacionais para a Educação Profissional de Nível Técnico, ítem 4 - Educação Profissional na nova LDB (grifo nosso)

${ }^{25}$ MEC Res.CNE/CEB n 04/99 - institui as diretrizes curriculares nacionais para a educação profissional de nível técnico

${ }^{26}$ Competência humana - “ (...) fundada instrumentalmente no manejo da educação e do conhecimento," na qual o "conhecimento é a instrumentação técnica mais fundamental da intervenção na realidade, apontando para a relevância da "qualidade formal", enquanto a educação aparece como instrumentação fundamental da cidadania, apontando para a "qualidade política". "Para o mercado, interessa a qualidade formal, ou seja, a capacidade do trabalhador manejar conhecimento inovador, fator determinante da competitividade; não interessa a qualidade política (...) Ver DEMO,1997,p9 e também FRIGOTTO, 1995.

27 Idem, ibidem

${ }^{28}$ BRASIL, MEC.Parecer CNE/CEB n 16/99- ítem 4- Educação Profissional na nova LDB.

${ }^{29}$ BRASIL, MS.1999 p28

\section{REFERÊNCIAS BIBLIOGRÁFICAS}

BRASIL, Ministério da Educação. LDB n 9.394/96 Capítulo II

Decreto $2.208 / 97$

Parecer CNE/ CEB n 16/ 1999

RES.CNE/CEB n 04/99 -

Parecer CNE/CEB n ${ }^{\circ}$ 10/200 
Referenciais Curriculares para a educação profissional de nível técnico. Texto introdutório, versão preliminar. Brasilia, DF: SEMTEC/CGEP, 2000 (Mímeogr.).

Ministério da Saúde. Saúde da Família: uma estratégia para a reorientação do Modelo Assistencial, 1997. 1999.

Seminário de Experiências Internacionais em Saúde da Família: Relatório Final Brasília, DF, p. 28,

Ministério o Trabalho e Emprego .LEITE, Elenice M. Educação Profissional no Brasil: construindo uma nova institucionalidade.Sefor.Brasília:1996 (mímeo)

Poder Executivo. Decreto 3.189/99

CEPAL Equidad y Transformación Productiva - Un enfoque integrado. 1992, opus cit in DEMO, Pedro. Educação Profissional: O debate da(s) Competência (s) MTb. Sefor. Brasília:1997

FRIGOTTO, Gaudêncio. Educação e a Crise do Capitalismo Real. Cortez, SãoPaulo: 1995.

Educação e Formação Técnico-Profissional Frente à Globalização Excludente e o Desemprego Estrutural . Revista do SEPE/RJ, Novembro de 1999Ábril de 2000- Ano2-Nºs 5 e 6, Edição Especial

MEHEDFF, Nassim G. A era da empregabilidade, O Globo, 9 de outubro de 1996

A nova educação profissional. LIDA Ministério da Saúde v. 1, n. 3, p. 78, jul/ago. 1997. Revista do Ministério do Trabalho

MENDES, Eugênio. Vilaça . Uma Agenda para a Saúde. 2. ed. Hucitec: São Paulo, 1999.

SANTOS. Milton. Por uma outra globalização - do pensamento único à consciência universal. Rio de Janeiro: Record, 2000. 